\title{
改訂セルフ・モニタリング尺度の検討
}

\author{
京都中央看護專門学校 石 原 俊 一1 \\ 同志社大学水野邦夫
}

\section{A study of revised Self-Monitoring Scale}

Shunichi Ishihara (Kyoto Central Nursing School, Minami-ku, Kyoto 601) and Kunio Mizuno (Department of Psychology, Faculty of Letters, Doshisha University, Kamigyo-ku, Kyoto 602)

The present study attempted to construct the Japanese version of Revised Self-Monitoring Scale (Lennox \& Wolfe, 1984). Factor analysis of this scale yielded two factors: 1) Sensitivity to expressive behavior of others, 2) Ability to modify self-presentation. This scale and its two factors had acceptable internal consistency: these results were almost similar with the original study. In correlational analyses with other personality measures, this scale correlated positively with both Private and Public Self-Consciousness Scale and Maudsley Personality Inventory-E Scale, but positively or negatively with some scales of Yatabe-Guilford Personality Inventory (e.g., G, S: positively. I, T: negatively.). Moreover the correlations between the two factors and the above mentioned measures provided interesting results. The availability of this scale was discussed.

Key words: social behavior, Self-Monitoring, self-presentation, sensitivity to others, test validity.

Snyder (1974) の提唱したセルフ・モニタリング (Self-Monitoring, 以後 SM と略記) は, 状況や個体に 対する関心の個人差に注目したという点において評価さ れ得るものであり, 社会行動を理解する上で重要な要因 と考えられる.

SM とは, 対人場面において状況や他者の行動を観察 し, 自己表出 (個人の表出行動) や自己呈示 (意戝的な印 象操作)が社会的に適切かどうかを考慮して自分の行動 を統制することである.すなおち周囲の状況や他者の行 動などの状況要因に影響されやすい人は SM 傾向が強 く(高い SM, 以後 HSM と略記), 逆に自己の内的状態 や気質などの個体要因に影響されやすい人は SM 傾向 が弱い（低い SM, 以後 LSM と略記）とされる.

さらに Snyder は SM 傾向の程度を測定する尺度と して, 基本的な 5 つの構成概念を基に 25 項目からなる SM 尺度 (以後 SMS と略記) を作成した。

しかし近年, SMS に詨する批判や問題点がいくつか 指摘されている.たとえば Briggs, Cheek, \& Buss (1980) はSMS の項目群を因子分析した結果, “外向性”. “演技性”.“他者志向性”の 3 因子を抽出した. その 他にも因子分析法によって SMS の下位構造を調べた研

1 本論文をまとめるにあたりご指導を賜りました同志 社大学文学部教授 橋本 宰先生に心より感謝申し上げ ます。
究は多くみられる (Gabrenya \& Arkin, 1980; 岩淵・田 中・中里, 1982; Ahmed, Garg, \& Braimoh, 1986) が, これらの結果は Snyder のいう SM の構成概念と必ず しも一致していないといえる。をた Briggs et al. は，自 尊心やシャイネスの尺度において, 他者志向性と外向性 の 2 つ下位次元間に逆方向の相関が見られ，この尺度 が単一次元のものではなく複数の下位尺度で構成されて いると指摘した。

これらの一連の研究を承けて, Lennox \& Wolfe (1984) は SMS に対して，1) Snyderの掲げた SM の 5 つの構成概念は, その内容に拈いて重複している部分が あるために，より単純にまとめることが可能である，2) $5 つ$ 構成概念のうち外向性や演技性に対応するものが ない，3）尺度としての内的整合性がそれほど高くない, 4) Briggs et al. の指摘にあるように，相容れない因子 （外向性因子と他者志向性因子）が同一尺度内に存在し， SM の概念と SMS で測定されている内容との閒に相 違がある，という問題点を呈したうえで, SMS の再構 成を試み，改訂 SMS (Revised Self-Monitoring Scale, 以後 RSMS と略記) を作成した. その因子分析の結果, Lennox \& Wolfe は RSMS が “自己呈示を修正する 能力”と“他者の表出行動への敏感さ”の 2 因子から なることを見出している.これに対して, Snyder \& Gangestad (1986) は測度の偏狭さや逆転項目の少なさな どを挙げながら RSMSを批判しており，RSMSに対す 
Table 1

Item wording, item scoring key, factor loading, and factor contribution for RSMS

\begin{tabular}{|c|c|c|c|}
\hline Item and scoring keya) & Factor 1 & Factor 2 & $h^{2}$ \\
\hline 1. 社会的な場面で，他の人が望むように，自分の行動を変えることができる. (T) & 13 & .52 & .28 \\
\hline 2. よく，人の目を見てその本当の気持ちを正確に読み取ることができる. $(\mathrm{T})$ & .70 & .20 & .53 \\
\hline 3. 他の人にこう印象つうけたいと思うつき合い方をコントロールすることができる. $(\mathrm{T})$ & .29 & .58 & .42 \\
\hline 4. 会話をしているとき，一緒にいる人のごく微妙な表情の変化にも敏感である. (T) & .70 & .12 & .51 \\
\hline 5. 私の直感力は，人の感情や動機を理解するときには，十分によい働きをする. $(\mathrm{T})$ & .69 & .16 & .50 \\
\hline $\begin{array}{l}\text { 6. 他の人が, あるジョークを聞いて， うわべはなるほどと思って笑っているようでも } \\
\text { 心の中では，趣味の悪いジークだと考えているときには，たいていそれが分か } \\
\text { る. (T) }\end{array}$ & .57 & .16 & .35 \\
\hline $\begin{array}{l}\text { 7. 自分の描くイメージが相手に伝わっていないと感じでいるとき，それを役立つよう } \\
\text { なイメージにたやすく変えることができる. (T) }\end{array}$ & .23 & .35 & .17 \\
\hline 8. 普通相手の目を読み取って自分が何か不適切なことを言ってしまったかが分かる(T) & .65 & .17 & .46 \\
\hline 9. 様々な人や様々な状況に合わせて行動を変えるのに苦労する. (F) & .13 & .50 & .27 \\
\hline 10. 自分の置かれているどんな状況にも適した行動をとることができる. (T) & .21 & .61 & .41 \\
\hline $\begin{array}{l}\text { 11. 他の誰かが私に噳をついていれば，普通その人の表現の仕方からすぐにそれが分か } \\
\text { る. (T) }\end{array}$ & .46 & .14 & .23 \\
\hline $\begin{array}{l}\text { 12. たとえそうすれば自分にとって有利になる場合でも，相手によい態度を装うことが } \\
\text { でき難い。(F) }\end{array}$ & -.01 & .37 & .13 \\
\hline $\begin{array}{l}\text { 13. 周囲がそのように要求していると分かれば，それに応じて行動を調節するのは簡単 } \\
\text { である。 }(\mathrm{T})\end{array}$ & .18 & .67 & .48 \\
\hline
\end{tabular}

Pct of $\operatorname{Var}(\%)$

$32.39 \quad 13.29$

a) $\mathrm{T}=$ true; $\mathrm{F}=$ false, $\mathrm{T}$ denotes items corded in direction of high Self-Monitoring

る議論は現状では十分であるとはいえず, SM 研究の発 展といら点からしても，一層の検討が必要であると思わ れる。

また日本語版 RSMS に関する研究についてもこれま でいくつか試みられてきた（堀毛，1986；岩淵・田中， 1987)が，これらは因子分析の結果などを比較すれば, Lennox \& Wolfe の研究とは必ずしも対応しておらず, RSMS の日本語版の作成は重要な問題であろう.

そこで本研究では RSMS の日本語版の作成を目的と し, その尺度の内的構造の分析や他の人格特性検査との 比較をとおしてその関連的妥当性を検討するとともに, $\mathrm{SM}$ の概念そのものを新たな角度から解明する手掛かり を探るものである。

\section{方法}

質問紙 改訂セルフ・モニタリング尺度 (RSMS : Lennox \& Wolfe, 1984). 13 項目で構成されており, “非常にそうである”から“全くそうでない”の6 件 法で回答を求めた。

性格検査（a) 自意識尺度（SC：Self-Consciousness， 菅原，1984). 21 項目で構成され，自己の外的あるいは 公的な (public) 側面である公的自意識と自己の内的あ るいは私的な (private) 側面である私的自意識の 2 因子
を含む。店形式は“非常に当てはまる”から“全く 当てはまらない”の7 件法である. (b) MPI (Maudsley Personality Inventory, Eysenck, 1962 MPI 研究会訳, 1964). (c) YG 性格検查 (辻网, 1965).

被調査者 $\mathrm{D}$ 大学の学生 543 名に調査の協力を求め た.このうち回答の記大もれがあった 8 名を除く 535 名 (男 350 名, 女 195 名)を分析対象とした. ただし, 各性 格検查は同様のサンプル集団から回答を求めたが，施行 された時期が若干異なるため，SC では 331 名（男 197 名, 女 134 名), MPI では 364 名 (男 221 名, 女 143 名), YG では 341 名(男 213 名, 女 128) に有効な回答が得ら れた. したがって，これらの尺度との関連する分析では それぞれのサンプル数を用いた.

結果

RSMS の因子分析 RSMS の13 項目に対し, 主成 分分析後のバリマックス回転による因子分析を行った. 固有值 1.0 以上で打ち切った結果, 2 因子が抽出された。 なお，性差については多少認められた程度であった. 第 1 因子 $(4,2,5,8,6,11$ の項目で構成される) は，相手の 表出行動に敏感で, 洞察力に富んでいる“他者の表出 行動への感受性 (Sensitivity to expressive behavior of others)"を示す因子であり, Lennox \& Wolfe (1984) 
Table 2

Correlations of Revised Self-Monitoring scale and its factors with other personality measures

\begin{tabular}{|c|c|c|c|c|c|}
\hline & & $\begin{array}{c}\text { Full } \\
\text { scale } \\
\text { of RSM }\end{array}$ & $\begin{array}{l}\text { Sensi- } \\
\text { tivity } \\
\text { scale }\end{array}$ & $\begin{array}{l}\text { Ability } \\
\text { to modify } \\
\text { scale }\end{array}$ & \\
\hline Private & $\mathrm{eSC}$ & $.26 * * *$ & $.33 * * *$ & .09 & \\
\hline Public & $\mathrm{SC}$ & $.20^{* * * *}$ & $.20 * * *$ & $.13^{*}$ & $N=331$ \\
\hline \multirow[t]{3}{*}{ MPI } & $\mathrm{E}$ & $.37 * * *$ & $.22^{* * *}$ & $.41 * * *$ & \\
\hline & $\mathrm{N}$ & -.02 & $.10^{+}$ & $-.13^{*}$ & \\
\hline & $\mathrm{L}$ & .09 & .03 & $.12^{*}$ & $N=364$ \\
\hline \multirow[t]{12}{*}{$\mathrm{YG}$} & $\mathrm{D}$ & -.09 & -.001 & $-.15^{* *}$ & \\
\hline & $\mathrm{C}$ & -.05 & .04 & $-.13^{*}$ & \\
\hline & 1 & $-.20 * *$ & $-.11^{+}$ & $-.23^{* * *}$ & \\
\hline & $\mathrm{N}$ & $-.10^{+}$ & .02 & $-.19 * * *$ & \\
\hline & $\mathrm{O}$ & -.01 & .08 & $-.10^{+}$ & \\
\hline & $\mathrm{CO}$ & -.04 & -.01 & -.07 & \\
\hline & $\mathrm{AG}$ & $.15^{* * *}$ & $.22 * * *$ & .02 & \\
\hline & G & $.45 * * *$ & $.29 * * *$ & $.46^{* * * *}$ & \\
\hline & $\mathrm{R}$ & $.12 *$ & .03 & $.16^{* * *}$ & \\
\hline & $\mathrm{T}$ & $-.12^{*}$ & $-.24 * * *$ & .05 & \\
\hline & A & $.34 * * *$ & $.23^{* * *}$ & $.34 * * *$ & \\
\hline & $\mathrm{S}$ & $.36^{* * *}$ & $.24 * * *$ & $.36 * * *$ & $N=341$ \\
\hline
\end{tabular}

が見出した因子と全く同様な項目を含んでいる. 第 2 因 子 $(13,10,3,1,9,12,7$ の項目で構成される) は, “自己 呈示の修正能力 (Ability to modify self-presentation)" を示す因子であり，第 1 因子と同様, Lennox \& Wolfe と全く同様な項目で構成されている. 因子分析の結果に ついては Table 1 に示した.

以上の結果に基づき RSMS を作成した。また, それ ぞれの下位尺度の構成基準として因子負荷量 .35 以上を 採用し, “他者の表出行動への感受性”を示す感受性尺 度と“自己呈示の修正能力” を示す修正能力尺度を構 成した. そして, 尺度使用時の簡便さや実用性を考慮し て，各下位尺度に含まれる項目の粗点をそれぞれ単純加 算し，尺度間のピアンンの相関係数を算出した結果，比 較的高い正の相関が認められた $(r=.41, p<.001)$. さら に, 各下位尺度の内的整合性を示す $\alpha$ 係数を求めたと ころ, RSMS 全体では .81, 感受性尺度 (6 項目) では .80 , 修正能力尺度 (7 項目) では .73 であった。

RSMS と他の性格検査との相関 RSMS 全体および 各下位尺度と $\mathrm{SC}, \mathrm{MPI}, \mathrm{YG}$ とのピアンンの相関係数 を Table 2 に示した. RSMS 全体では私的, 公的自意 識両尺度にやや低い正の相関が見られ，MPI の外向性 （E）尺度に比較的高い正の相関が見られた。ささらに YG
の愛想の悪さ (AG), 一般活動性 (G), のんきさ $(R)$ の活 動性因子群 ( $\mathrm{AG}, \mathrm{G})$ および衝動性因子群 $(\mathrm{G}, \mathrm{R})$ に正 の相関が認められ, 支配性 (A), 社会的外向性 (S) の主 導性因子群に正の相関が見られた。感受性尺度は， SC の両因子および MPI の外向性尺度に正の相関が見ら れ，YG の活動性因子群および主導性因子群と正の相関 が認められた. 修正能力尺度は, SC の公的自意識尺度 とのみ低い正の相関が見られた，MPI では外向性尺度 に比較的高い正の相関が見られ，虚偽 (L) 尺度に比較的 低い正の相関が認められた。さらに YGでは抑らつ(D) 尺度, 回帰性 $(\mathrm{C})$, 劣等感 (I) 尺度㧍よび神経質 $(\mathrm{N})$ 尺 度の情緒不安定性因子群に一貫して負の相関が見られ, 衝動性因子群および主導性因子群には正の相關が見られ た.

\section{考察}

本研究では, Lennox \& Wolfe (1984) が提出した改訂 セルフ・モニタリング尺度の日本語版の作成を試みた. その結果, 他者の表出行動への感受性と自己呈示の修正 能力の 2 因子が抽出され, Lennox \& Wolfe と全く同様 であった。しかし，彼らの結果では自己呈示の修正能力 因子功第1 因子として見いだされており，本研究と異な っていた.この差異については, 本研究では解釈は困難 であり, その重要性については今後の検討課題であろ う.また，固有值が第 1 因子から 4.21, 1.72,0.96 と第 1 因子に比較的大きい值が示されており, 各下位尺度の内 的整合性がほぼ十分に認められるものの, RSMS の構 造惊次の単一次元で説明できる可能性を示しているの かもしれない.このことは, Snyder の SMS において 理論的に整合性の低い部分を削除し, SM の構成概念と の対応を目的とした Lennox \& Wolfe の立場を支持す ると考えられる。ただし, Snyder らの主張通り, 尺度 の内容を狭くしている疑いも否定できない. 次に, SC (私的・公的自意識), MPI, YG との関連を検討したと ころ, SC の私的自意識では Lennox \& Wolfe の結果 と一致していたが，公的自意識では両尺度とも正の相関 が見られた。本来，公的自意識の尺度は他者からの評洒 的態度に敏感で (Fenigstein, 1979)，他者の目を意識し て自己表出をコントロールする (Scheier, 1980; Carver \& Humphries, 1981) 傾向を測定する尺度であるため, 正の相関が見出されたと考えられる. MPI の虚偽尺度 との関連では, 自己呈示の修正能力因子において正の相 関が見られ，社会的に望ましい傾向を示す因子と考えら れる. YG との関連では, 他者の表出行動への感受性 因子は, より刺激を求め, 活動的であり, 主導的な傾向 を示し，社会的な適切さを示す手がかりを感知すること に有効であると考えられる. 一方, 自己呈示の修正能力 因子は，情緒の安定性を示している.この関連性におけ 
る解勫については，ます，情緒の安定性を示すことによ り, 社会的に望ましい自己呈示, 特に感情表出を行う上 で, 有効的に作用すると考えられ，また別の側面から見 ると, 自己の内的状態と状況の要求との不協和による感 情の混乱に対して耐性を生じさせる效果があるとも考え られる。

最後に, HSM 者は内的状態と顕在的行動との間に ほとんど斉合性を示さないという指摘がある (Snyder, 1979). 事実, 本研究においても他者の表出行動の認識に 扮ける評価と実際に行う自己呈示とは異なった次元で示 され，必ずしも内的状態と行動が一致するとは限らない が，MPI の外向性尺度や YG の G, A, S 尺度が両因子 に共通して正の相関が認められたことは，内的状態と表 出行動の間に社会的望ましさを背景とした傾向が一貫し て見られ，両者間に斉合性がもたらされることを示唆す るのかもしれない. しかしながら，HSM 者の内的過程 については, Snyder むかなりの思弁的な色彩が強く, 今後行動的側面を含む多方面からの検討が必要である 亏.

\section{引用文献}

Ahmed, S. M., Garg, R., \& Braimoh, G. 1986 Psychometric of Snyder's self-monitoring of expressive behavior scale. Perceptual and Motor Skill, 63, 495-500.

Briggs, S. R., Cheek, J.M., \& Buss, A.H. 1980 An analysis of the self-monitoring scale. Journal of Personality and Social Psychology, 38, 679-686.

Carver, C.S., \& Humphries, C. 1981 Havana daydreaming: A study of self-consciousness and the negative reference group among Cuban-Americans. Journal of Personality and Social Psychology, 40, 545552.

アイゼンク H.G. MPI 研究会(訳) 1964 モーズレイ 性格检查 誠信書房

(Eysenck, H. G. 1962 Maudsley personality inven- tory. San Diego, Calif. : Educational and Industrial Testing Service.)

Fenigstein, A. 1979 Self-consciousness, self-attention, and interaction. Journal of Personality and Social Psychology, 37, 75-86.

Gabrenya, W.K., \& Arkin, R.M. 1980 Self-monitoring scale: Factor structure and correlates. Personality and Social Psychology Bulletin, 6, 13-22.

堀毛一也 1986 自己モニタリングの概念および尺度に 関寸る検討 東北福祉大学紀要，11，185-199。

岩淵千明・田中国夫 1987 セルフ・モニタリング尺度 改訂版への試み 日本社会心理学会第 28 回大会発表 論文集, 67.

岩淵千明・田中国夫・中里浩明 1982 セルフ・モニタ リング尺度に関する研究 心理学研究，53，54-57.

Lennox, R.D., \& Wolfe, R.N. 1984 Revision of Self-Monitoring Scale. Journal of Personality and Social Psychology, 46, 1349-1364.

Scheier, M. F. 1980 Effects of public and private self-consciousness on the public expression of personal beliefs. Journal of Personality and Social Psychology, 39, 514-521.

Snyder, M. 1974 The self-monitoring of expressive behavior. Journal of Personality and Social Psychology, 30, 526-537.

Snyder, M. 1979 Self-monitoring processes. In L. Berkowitz (Ed.), Advances in experimental social psychology (Vol. 12). New York: Academic Press. Pp. 85-128.

Snyder, M., \& Gangestad, S. 1986 On the nature of self-monitoring: Matters of assessment, matters of validity. Journal of Personality and Social Psychology, 51, 125-139.

菅原健介 1984 自意識尺度 (self-consciousness scale) 日本語版作成の試み 心理学研究，55，184-188.

辻岡美延 1965 新性格検査法 竹井機器工業株式会社 